\title{
Seed dispersal in the seagrass Zostera marina is mostly within the parent bed in a protected bay
}

\author{
Shinya Hosokawa ${ }^{1, *}$, Masahiro Nakaoka ${ }^{2}$, Eiichi Miyoshi ${ }^{3}$, Tomohiro Kuwae ${ }^{3}$ \\ ${ }^{1}$ Marine Environmental Information Group, Port and Airport Research Institute, 3-1-1 Nagase, Yokosuka, \\ Kanagawa 239-0826, Japan \\ ${ }^{2}$ Akkeshi Marine Station, Field Science Center for Northern Biosphere, Hokkaido University, Akkeshi, Hokkaido 088-1113, \\ Japan \\ ${ }^{3}$ Coastal and Estuarine Environment Research Group, Port and Airport Research Institute, 3-1-1 Nagase, Yokosuka, \\ Kanagawa 239-0826, Japan
}

\begin{abstract}
Seed production and dispersal are key processes in plant population dynamics and gene flow. However, few quantitative studies have followed these processes in aquatic plants. We investigated the abundance of seeds produced and dispersed by the seagrass Zostera marina L. at a protected site within an enclosed bay. We also examined the buoyancy potential of seed dispersal units (diaspores) in the laboratory. Field observations showed that $31 \%$ of the total potentially produced seeds were dispersed as decayed reproductive shoots on the sea bottom of the parent bed, whereas $14 \%$ were dispersed in spathes (a component of reproductive shoots; seeds are contained inside) detached from live reproductive shoots. However, more than half of the dispersed spathes were negatively buoyant because of the weight of the ripe seeds they contained. Thus, $<6 \%$ of potentially produced seeds were dispersed by rafting away from the parent bed. The abundance of ripe seeds dispersed was comparable to that of seeds in the parent bed sediment. The fate of the remaining $54 \%$ of total potentially produced seeds was not detected, and they were assumed to be immature or to have been consumed by herbivores. Fewer than $5 \%$ of the dispersed seeds had germinated. Our results show that most seeds were dispersed within the parent bed, supporting one of the fitness-related seed-dispersal hypotheses, namely that dispersal mechanisms play a role in bed maintenance and increased genetic diversity.
\end{abstract}

KEY WORDS: Buoyancy potential - Eelgrass - Recruitment - Seed dispersal - Seed fate · Seed production

Resale or republication not permitted without written consent of the publisher

\section{INTRODUCTION}

The success of seed dispersal, seed survival in soils, germination, and seedling growth are central in the ecology of plant populations (Bakker et al. 1996). Seed dispersal is the most important process for escaping from density- or distance-dependent seed and seedling mortality and for colonizing suitable new sites, which can be unpredictable in space and time (Howe \& Smallwood 1982). The distribution of recruitment is strongly related to the distance of seed dispersal (Nathan \& Muller-Landau 2000, Bischoff 2002); the dispersal distance is determined by the dispersal environment and by the physical and biological properties of the seed dispersal unit (diaspore) (Howe \& Smallwood 1982, Nathan \& MullerLandau 2000, Nathan et al. 2002).

For marine aquatic angiosperms, seed dispersal is the most important process for the maintenance and persistence of their populations (Kendrick et al. 2012). Their seed-dispersal distance depends on the residence time of seeds rafting on the water surface, on the current speed (Harwell \& Orth 2002, Boedeltje et al. 2004, Erftemeijer et al. 2008, Källström et al. 2008, Coleman et al. 2011a,b), and on the activity of seed consumers (Sumoski \& Orth 2012). These mech- 
anisms can disperse seeds to a range of hundreds of kilometers and genetically connect separate populations (Kendrick et al. 2012).

The seagrass Zostera marina has 2 seed dispersal modes: (1) short-distance dispersal around the parent population driven by the dominant force of gravity (Orth et al. 1994) and (2) long-distance dispersal far from the parent population through rafting on the water surface (Harwell \& Orth 2002, Erftemeijer et al. 2008, Källström et al. 2008, Kendrick et al. 2012). The spathe (a component that includes seeds; Granger et al. 2002), rhipidium (a group of spathes; Granger et al. 2002, Harwell \& Orth 2002), and reproductive shoot of Z. marina (Fig. 1A) are well-known diaspores for seed dispersal and are expected to experience different fates. Because these diaspores may have different dispersal mechanisms, they may have different roles in population dynamics, such as the establishment of new populations by rafting (Harwell \& Orth 2002, Erftemeijer et al. 2008, Källström et al. 2008, Kendrick et al. 2012) or the re-establishment of a population by short-distance seed dispersal (Plus et al. 2003, Greve et al. 2005, Lee et al. 2007). However, if $Z$. marina were specialized for either long- or shortdistance seed dispersal, it would risk limiting the re-

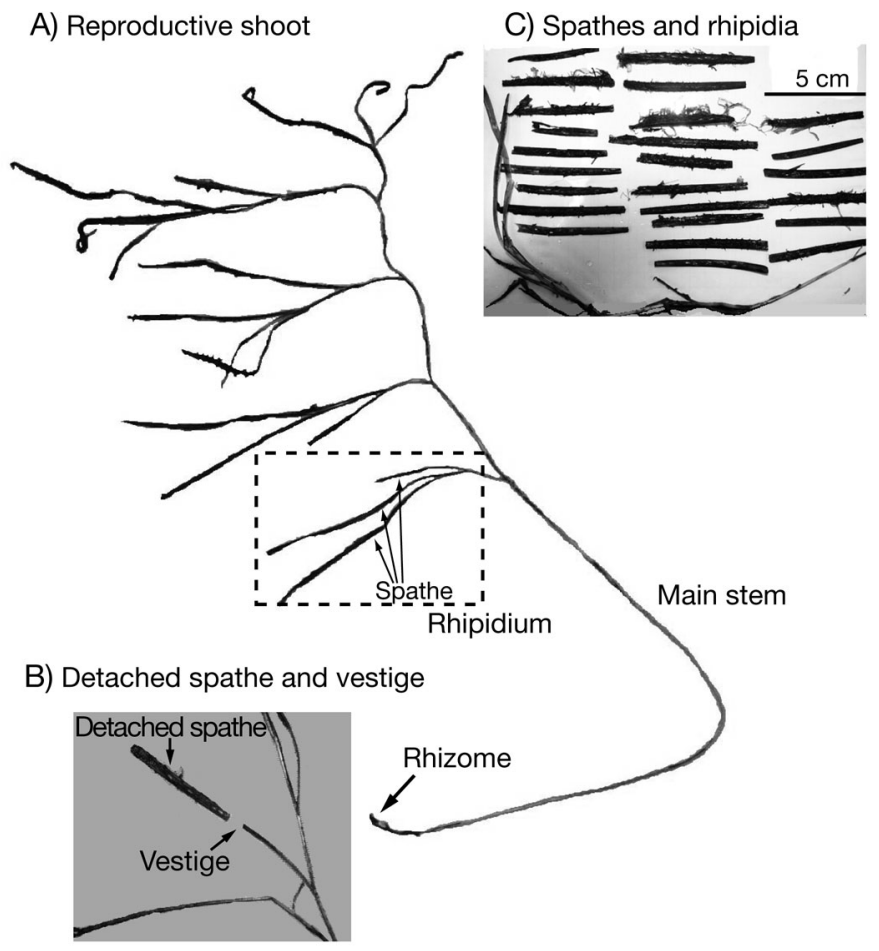

Fig. 1. Morphology of the eelgrass reproductive shoot. (A) An overview of the reproductive shoot, showing rhipidia and spathes. (B) An example of a separated spathe and its vestige. (C) A sample of spathes and rhipidia that washed up along the shore of Kurihama Bay, Japan establishment of lost populations or the establishment of new populations, respectively.

In this study, we quantitatively investigated the processes of seed production, the abundance of seeds dispersed via diaspores, and seedling density in the seagrass $Z$. marina (eelgrass) in Kurihama Bay, central Japan $\left(35^{\circ} 13.5^{\prime} \mathrm{N}, 139^{\circ} 42.8^{\prime} \mathrm{E}\right)$. Eelgrass was chosen as a model seagrass because it has various diaspores and is a well-studied aquatic plant worldwide. Kurihama Bay was also chosen as a model site because it is located at the mouth of Tokyo Bay, where the spatial gradients of water temperature and salinity are gradual (Guo \& Yanagi 1996), and there are other eelgrass beds near the study site (Shoji \& Hasegawa 2004, Tanaka et al. 2011). In addition, we used laboratory experiments to examine the watercolumn dynamics of the diaspores, specifically whether they have negative or positive buoyancy.

Little is known about the function of diaspores in eelgrass populations. Seed dispersal both near the parent plants and far from them would increase the chances of wide-ranging dispersal and reduce the risks resulting from limited seed-dispersal distance. However, because the dominant driving forces behind these dispersal mechanisms would be different—gravity for local dispersal (Orth et al. 1994) and buoyancy for distant dispersal (Harwell \& Orth 2002, Erftemeijer et al. 2008, Källström et al. 2008, Kendrick et al. 2012) — we hypothesized that dispersal by either mechanism could be limited for an eelgrass bed at a calm site. To test this hypothesis, we determined the proportions of seeds dispersed via different diaspores, and the proportions of these diaspores with positive or negative buoyancy, in an eelgrass bed in Kurihama Bay. In addition, we estimated the proportions of rafted and sunken seeds in the field by linking these quantitative empirical data. Finally, we determined the proportion of dispersed seeds that produced seedlings and assessed the effects of seeds that settled within the parent bed.

\section{MATERIALS AND METHODS}

\section{Study site}

The studied eelgrass bed lies along the shoreline in Kurihama Bay, which is partially enclosed by breakwaters constructed at the mouth of the bay as part of the port facilities (Fig. 2A). The perennial eelgrass bed became established before 2000; it is now approximately $300 \mathrm{~m}$ in length and in water depths of 0.4 to $1.6 \mathrm{~m}$ (Fig. 2B). The cross-shore slope around 

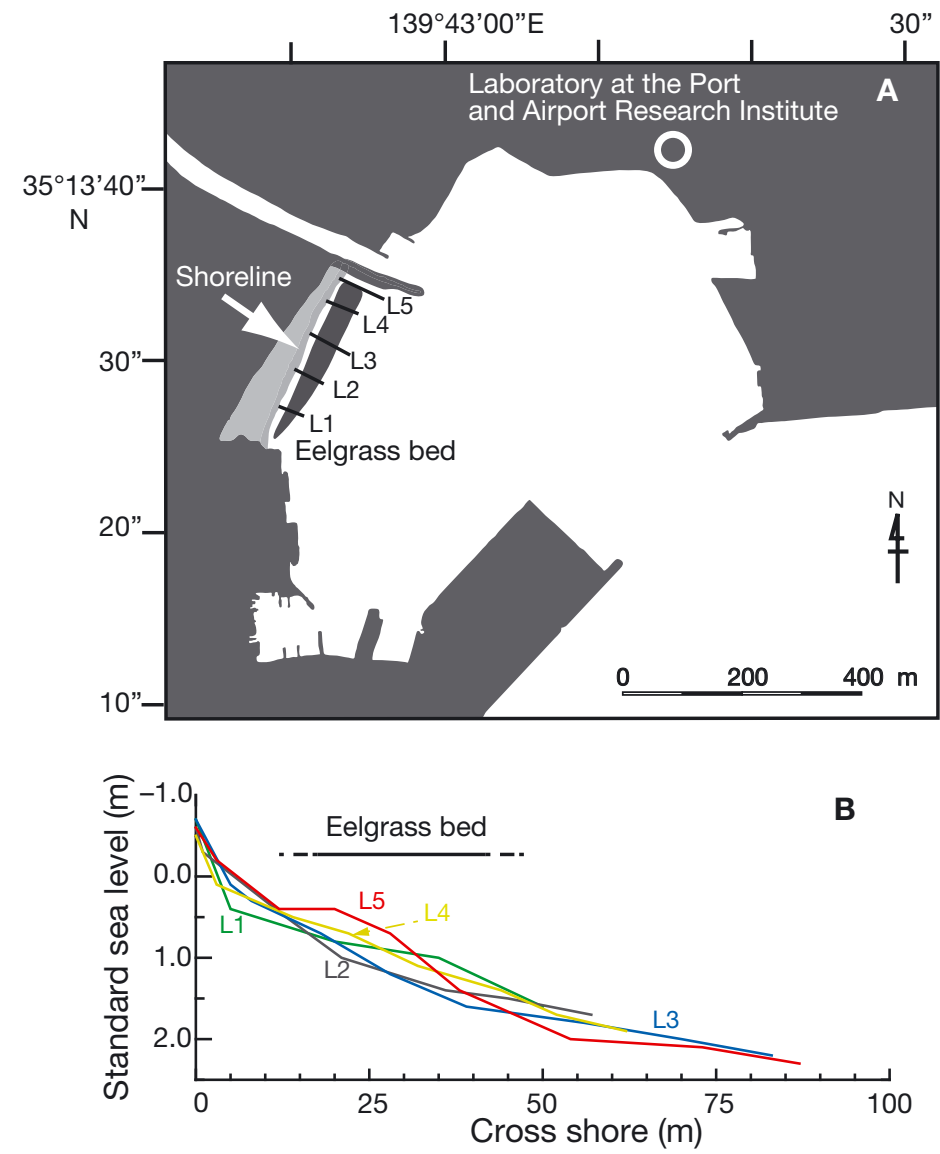

Fig. 2. Study area in Kurihama Bay, Kanagawa, Japan. (A) Locations of the eelgrass bed (black area) and shoreline (gray shading) and (B) topographic profiles across the shoreline and through the eelgrass bed. Lines L1 to L5 in (A) were used for the profiles shown in (B). Samples were transported to the laboratory at the Port and Airport Research Institute for further study

the shoreline is between approximately 1:15 and 1:5. Median sand grain size around the shoreline is $0.52 \mathrm{~mm}$, similar to sand at sites Hashirimizu and Tomyosaki near the study site (see Supplement 1 at www.int-res.com/articles/suppl/m523p041_supp. pdf). During the study period, most of the bed was covered with eelgrass, although there were bare spots with exposed sediment in parts of the bed.

\section{Reproductive shoots and seed production}

Perennial eelgrass has both vegetative and reproductive shoots (Phillips et al. 1983, Nakaoka \& Aioi 2001). Reproductive shoots occur in the flowering season and account for $<15 \%$ of the total number of shoots in the flowering season in Japanese waters (Nakaoka \& Aioi 2001). Reproductive shoots decay after seed production. For this study, a 'live' reproductive shoot was defined as a reproductive shoot before it decayed; live reproductive shoots have spathes and rhipidia (Fig. 1A) and vestiges of spathes and rhipidia (Fig. 1B). A reproductive shoot that had decayed on the sea bottom but was still anchored was defined as a 'decayed' reproductive shoot.

Male and female flowers are arrayed together in a spathe (Granger et al. 2002). The ovary, which is part of the female flower, produces a seed on a spathe. After the ovary wall splits, a ripe seed is exposed (Granger et al. 2002). In this study, ovaries that still had the female flower parts (stigma and style) were defined as flowers, and ovaries before the ovary wall split were defined as immature seeds. Whole seeds can be either immature or ripe.

The densities of vegetative and reproductive shoots were measured from March to August in 2010 using an arbitrarily placed quadrat. The quadrat was $0.09 \mathrm{~m}^{2}$ in March $(\mathrm{n}=51)$ and was increased to $0.25 \mathrm{~m}^{2}$ during the reproductive season from May to August ( $\mathrm{n}=24$ per month) because of the low density of reproductive shoots relative to vegetative shoots. Live and decayed reproductive shoots were separately counted in situ to estimate the seasonal reproductive effort and the seed dispersal by decayed shoots.

Twenty live reproductive shoots were haphazardly sampled every month from May to August. In 2009, the shoots were collected by a researcher on foot from the shallower half of the bed while the water level was low, and in 2010, the shoots were collected from the entire area using SCUBA gear. The samples were carefully transported to our laboratory with a minimum of disturbance. In 2009, approximately half of the sampled reproductive shoots were placed together in each of 2 bags for transport. Because some reproductive shoots became fragmented into detached seeds, spathes, and rhipidia during transport, it was not possible to determine the quantitative associations between these components. To overcome this problem, in 2010, each sampled reproductive shoot was placed individually in a separate bag and transported. We counted the numbers of ripe and immature seeds, spathes, rhipidia, and their vestiges on the sampled reproductive shoots. If there were detached ripe and immature seeds, spathes, or rhipidia in a bag used for transport, these were also counted to correct the total numbers for a group of reproductive shoots transported together (2009) or for individual reproductive shoots (2010). Vestiges on the main stem were categorized on the basis of the components attached above and below the vestige in 
accordance with the nature of eelgrass growth, in that rhipidia develop sequentially from the bottom to the top of the main stem (Granger et al. 2002). Thus, a vestige between 2 rhipidia or between 2 spathes was categorized as a rhipidium or a spathe, respectively; that between rhipidium and spathe as 'unclear'; and that within a rhipidium as a spathe.

\section{Buoyancy of spathes and rhipidia}

Spathes and rhipidia were tested for buoyancy. The specimens tested were obtained from the live reproductive shoots sampled in 2009 and 2010 for the estimation of seasonal seed production. Ten additional reproductive shoots were sampled in July 2009 for buoyancy tests. Buoyancy potentials were tested in a bucket containing seawater obtained from Kurihama Bay, with a density of 1.02 (temperature: 21 to $25^{\circ} \mathrm{C}$; salinity: 32 to 34 ) measured by using a multiparameter water-quality meter (U-21XD; Horiba, Kyoto). Spathes and rhipidia were placed gently in the water to avoid attaching air bubbles and then observed for several seconds until their movements became stable on the surface or bottom.

Spathes that became detached from the parent reproductive shoots during transport were defined as 'detached spathes.' The spathes harvested by hand from the parent reproductive shoots were defined as 'harvested spathes.' The numbers of ripe and immature seeds in these spathes were counted. A total of 72 detached spathes and 894 harvested spathes were obtained. However, 9 detached spathes were excluded from examination because they were fragmented. Of those spathes examined, 17 detached spathes and 722 harvested spathes had no seeds. The remaining 46 detached spathes and 172 harvested spathes had $>1$ seed and were analyzed statistically for their buoyancy potential.

Rhipidia did not become detached during transport from the field, and 137 rhipidia were harvested and examined for buoyancy. Sampled live reproductive shoots were not examined for buoyancy because their positive buoyancy was apparent from their vertical orientation in the water column.

The specific gravity of ripe seeds collected in June and July 2009 was determined by pooling 50 randomly chosen ripe seeds ( $\mathrm{n}=3$ groups of 50 seeds). The mass of a group of 50 ripe seeds was determined. The volume of the group was measured by using a pycnometer of $25 \mathrm{ml}$, which was filled with filtered seawater. The specific gravity of ripe seeds was determined by dividing the mass of the group of ripe seeds by the volume and then by the mass of a unit volume of fresh water.

\section{Diaspores along the shoreline}

The diaspores that washed up along the shoreline of Kurihama Bay were sampled to determine the numbers transported (Fig. 1C). Because the diaspores consisted of different reproductive units, including separated spathes, rhipidia, and reproductive shoots, the number of spathes in each of these diaspore types was counted as a measure of dispersal. The numbers of individual seeds and seeds included in diaspores were not used in this assessment because accurate detection of seeds along the shoreline was difficult and because seeds would have left the diaspores during the dispersal process. Diaspores were collected along transect lines, which were haphazardly set along the shoreline, from June to August in 2009 and from May through August in 2010. The length of transect lines was shortened from $10 \mathrm{~m}$ in 2009 to $5 \mathrm{~m}$ in 2010 because the numbers of diaspores along transect lines in 2009 were too numerous to count and inefficient for statistical analysis. Along with the shorter transects, the number of transect lines was increased from 3 in 2009 to 6 in 2010 .

\section{Seeds in the sediment}

Seeds, fragments of seed coats buried in the sediment, and seedlings, both within and outside of vegetated areas, were haphazardly sampled using SCUBA gear within a quadrat (area: $0.09 \mathrm{~m}^{2} ; \mathrm{n}=5$ quadrats each within and outside of vegetation) in August and October 2010 and in January 2011 (30 quadrats in total). The sampling outside of the vegetated area was conducted within approximately $1.5 \mathrm{~m}$ of the edge of the eelgrass bed. Because eelgrass seeds have been reported to be buried to approximately $\leq 10 \mathrm{~cm}$ (Morita et al. 2007), seeds were sampled from the sediment to a depth of at least $10 \mathrm{~cm}$. To determine seed survivorship from the previous year, the abundances of seeds and seed-coat fragments within the eelgrass bed were measured via SCUBA in May 2010, before seeds were dispersed, using a shovel (area: $0.031 \mathrm{~m}^{2}$; sampling depth, at least $10 \mathrm{~cm} ; \mathrm{n}=5$ ). According to Orth et al. (1994), eelgrass seeds are $1.3 \pm 0.2 \mathrm{~mm}$ in length (mean \pm SD). Therefore, the sampled sediment was sieved in situ using a $1 \mathrm{~mm}$ mesh bag. The sieved 
sediment was transported to the laboratory for sorting and counting of seeds (i.e. those that settled undamaged through the water column) and seedcoat fragments. Seeds that could be easily compressed using tweezers were classified as seed-coat fragments.

\section{Statistical analysis}

Reproductive shoots and seed production

Monthly differences in the numbers of seeds produced and the density of live reproductive shoots were examined by the Kruskal-Wallis rank-sum test to assess their seasonality. In addition, differences in the numbers of ripe and immature seeds produced in live reproductive shoots were tested using the Wilcoxon signed-rank test. The Kruskal-Wallis ranksum test was used to examine (1) seasonal changes in the density of decayed reproductive shoots on the bay bottom and (2) differences in the number of vestiges of spathes and rhipidia in the 20 reproductive shoots sampled from the field.

\section{Buoyancy tests}

Spathes tested for buoyancy were classified as either 'floating' or 'sinking.' The proportion of floating spathes was then estimated using a generalized linear model with the explanatory variables of number of ripe seeds in a spathe, spathe either detached or harvested (categorical variable), experimental year either 2009 or 2010 (categorical), and inter-actions between variables (see Supplement 2 at www.int-res. com/articles/suppl/m523p041_supp.pdf). Although immature seeds in a spathe may affect the spathe buoyancy, immature seeds were excluded from this analysis because of their unclear degree of maturation. The Bernoulli error distribution with logistic function was applied to the proportional data. Maximum likelihood parameters were estimated using the ' $\mathrm{glm}$ ' function in the statistical software package R (R Development Core Team 2013). Akaike's information criterion (AIC) was used to compare the goodness of fit of candidate models. The AIC was adjusted to the bias-corrected AIC $\left(\right.$ QAIC $\left._{C}\right)$ because the ratio of the sample size to the number of predictor variables in the global model was <40 (Hurvich \& Tsai 1989, Burnham \& Anderson 2002). Spathes that contained no seeds were excluded from the model analyses to avoid biases.

\section{Diaspores along the shoreline}

Seasonal differences in the total number of drifting spathes, including separated spathes and those on rhipidia, and reproductive shoots were tested using the Kruskal-Wallis rank-sum test. In addition, the relative proportion of spathes in each type of diaspore (i.e. the number of spathes in a diaspore type divided by the total number of spathes) was estimated using the generalized linear mixed model (Bolker et al. 2009), with explanatory variables of normalized date, year (categorical, either 2009 or 2010), and an interaction between these as fixed factors and with transect lines as a random factor (Supplement 2). The explanatory variable of year was expected to include the effects of the different length of transect lines in the 2 years on the relative proportions of spathes. These are considered to be distinct from the effects of transect lines as a random factor, which would reflect the variability of the relative proportions of spathes among locations. A binomial error distribution with logistic function was applied to the proportional diaspore data. Maximum likelihood parameters were estimated using the 'glmmML' function in the R statistical package (Broström \& Holmberg 2011). The ranges of variability for the relative proportions of each diaspore type were calculated from the scale parameter (see Supplement 2). QAIC ${ }_{C}$ was used to compare the goodness of fit of candidate models.

\section{Seeds in the sediment}

Because there is spatial heterogeneity of seed density in the sediment for seagrass species (Inglis 2000), the measured abundances of seeds and seed-coat fragments in the sediment were assumed to be distributed heterogeneously. A generalized linear mixed model was used to test the effects of time, with normalized date (continuous explanatory variable), vegetated state (categorical explanatory variable; either with or without vegetation), and an interaction between these as fixed factors and with the sampling point as a random factor (see Supplement 2). A Poisson error distribution with log function was used for seed and seed-coat fragment abundances. Maximum likelihood parameters were estimated using the 'glmmML' function in the $\mathrm{R}$ statistical package (Broström \& Holmberg 2011). The ranges of variability in abundances were calculated from the scale parameter (see Supplement 2). QAIC $C$ was used for comparing the goodness of fit of candidate models. 


\section{Estimation of seed dispersal}

The densities of seeds on live reproductive shoots (a in Table 1), dispersed with decayed reproductive shoots $\left(b\right.$ and $\left.d^{\prime}\right)$, dispersed with detached spathes $(c$ and $\left.d^{\prime \prime}\right)$, and dispersed with rhipidia were determined in every reproductive month to assess the proportional contribution of different diaspores to seed dispersal. Densities of live and decayed reproductive shoots, the numbers of seeds on live reproductive shoots, the numbers of spathe vestiges on live reproductive shoots, and the numbers of seeds represented by the vestiges of spathes, which were obtained from field investigations, were used to estimate these seed densities (Table 1). For estimating $b$ and $d^{\prime}$, we assumed (1) that live reproductive shoots became decayed reproductive shoots while retaining seeds, spathes, and rhipidia and (2) that decayed reproductive shoots disappeared completely within the interval of our investigation. The latter assumption presumes that a decayed reproductive shoot observed at time $m-1$ disappeared by time $m$. Any reproductive shoot that decayed and disappeared during the interval between sampling was not detected. The value for a was the seed density on live reproductive shoots at time $\mathrm{m}$.
Values for $b, c, d^{\prime}$, and $d^{\prime \prime}$ were the densities of seeds dispersed during the month between $m-1$ and $m$.

The probability densities of the density of seeds on live reproductive shoots (a) and dispersed by decayed reproductive shoots $(b)$ were estimated to assess the variability of seed production and dispersal. The probability densities of $a$ and $b$ were determined by multiplying the probability densities of the variables used for determining $a$ and $b$ (see Table 1), which were reproduced by a bootstrap method for 10000 iterations. To compare their variability with that of sampled seeds in the sediment, the density of live and decayed reproductive shoots was calculated for an area of $0.09 \mathrm{~m}^{2}$, which was the quadrat size used for sampling seeds in the sediment, and not for $0.25 \mathrm{~m}^{2}$, which was the quadrat size used for sampling the reproductive shoots. The mean, maximum, minimum, and interquartile ranges of these abundances were determined from the simulations.

The estimation of the density of seeds dispersed by detached spathes ( $c$ and $d^{\prime \prime}$ ) requires knowledge of the number of spathe vestiges on live reproductive shoots at $m-1$ and at $m$ (Table 1 ). The estimation methods can determine the means but not probability densities.

Table 1. Relationships for estimating eelgrass seed densities. $a$ is the density of seeds in live reproductive shoots in month $m$. $b, c, d$, and $d^{\prime \prime}$ are densities of seeds dispersed by decayed reproductive shoots and spathes between months $m-1$ and $m$. A bar over variables indicates the mean value of the variables. $p()$ in $a$ and $b$ refers to the probability distribution of the variables in parentheses. $D S$ : density of seeds on live reproductive shoots; $D S D_{\text {decayed, } b}$ and $D S D_{\text {decayed, } d}$ : density of seeds dispersed by decayed reproductive shoots; $D S D_{\text {spathe,c }}$ and $D S D_{\text {spathe,d }}$ : density of seeds dispersed by spathes; $D L R_{m}$ and $D D R_{m}$ : densities of live and decayed reproductive shoots in month $m_{i} N S l r_{m}$ : number of live reproductive shoots in month $m_{i} V_{m}$ and $V_{m-1}$ : number of spathe vestiges in live reproductive shoots in months $m$ and $m-1 ; N S s p$ : number of seeds in spathe vestiges

\begin{tabular}{|c|c|c|c|c|c|c|c|}
\hline & \multirow{2}{*}{$\begin{array}{l}\text { Estimated seed density } \\
\left(\text { seeds } \mathrm{m}^{-2}\right)\end{array}$} & \multirow{2}{*}{ Equation } & \multicolumn{5}{|c|}{ Oobserved variables } \\
\hline & & & \multicolumn{2}{|c|}{$\begin{array}{l}\text { Density of } \\
\text { reproductive } \\
\text { shoots } \\
\left(\text { shoots } \mathrm{m}^{-2} \text { ) }\right.\end{array}$} & $\begin{array}{l}\text { No. of seeds in } \\
\text { live reproductive } \\
\text { shoots } \\
\left(\text { seeds shoot }{ }^{-1} \text { ) }\right.\end{array}$ & $\begin{array}{l}\text { No. of spathe } \\
\text { vestiges in live } \\
\text { reproductive } \\
\text { shoots } \\
\left(\text { vestiges shoot }^{-1}\right)\end{array}$ & $\begin{array}{l}\text { No. of seeds in } \\
\text { spathe vestiges } \\
\left(\text { seeds vestige }^{-1}\right)\end{array}$ \\
\hline \multicolumn{8}{|c|}{ Seeds attached to live reproductive shoots } \\
\hline & $p\left(D S_{m}\right), \overline{D S_{m}}$ & $p\left(D L R_{m}\right) \times p\left(N S l r_{m}\right)$ & $p\left(D L R_{m}\right)$ & & $p\left(N S l r_{m}\right)$ & & \\
\hline \multicolumn{8}{|c|}{ Dispersed seed } \\
\hline$b$ & $p\left(D S D_{\text {decayed }, b, m}\right), \overline{D S D_{\text {decayed }, b, m}}$ & $p\left(D D R_{m}\right) \times p\left(N S l r_{m}\right)$ & & $p\left(D D R_{m}\right)$ & $p\left(N S I r_{m}\right)$ & & \\
\hline & $\overline{\overline{D S D_{\text {decayed }, d, m}},}$ & Eq. (3) & & $\overline{D D R_{m}}$ & & $\overline{V_{m}}$ and $\overline{V_{m-1}}$ & $\overline{N S s p}$ \\
\hline \multicolumn{8}{|c|}{ Seeds dispersed by detached spathes } \\
\hline C & $\overline{\overline{D S D_{\text {spathe }, c, m}},}$ & Eq. (1) & $\overline{D L R_{m}}$ & & & $\overline{V_{m}}$ and $\overline{V_{m-1}}$ & $\overline{N S s p}$ \\
\hline$d^{\prime}$ & $\overline{D S D_{\text {spathe }, d, m}}$ & Eq. (4) & & $\overline{D D R_{m}}$ & & $\overline{V_{m}}$ and $\overline{V_{m-1}}$ & $\overline{N S s p}$ \\
\hline
\end{tabular}


The mean density of seeds dispersed by detached spathes (C), $\overline{D S D_{\text {spathe, }, m, m}}$ is calculated as follows:

$$
\overline{D S D_{\text {spathe }, c, m}}=\overline{D L R_{m}} \times\left(\overline{V_{m}}-\overline{V_{m-1}}\right) \times \overline{N S s p}
$$

where $\overline{D L R_{m}}$ is the mean density of live reproductive shoots, and $\overline{V_{m}}$ and $\overline{V_{m-1}}$ are the mean numbers of spathe vestiges on live reproductive shoots at times $m$ and $m-1$, respectively. $\overline{N S s p}$ is the mean number of seeds in detached spathes. Because $\overline{N S s p}$ could not be measured, it was estimated from the detached spathes that were used for the buoyancy tests. To determine the means of $d^{\prime}$ and $d^{\prime \prime}$, the number of spathe vestiges on decayed reproductive shoots, $\overline{D D R} \times \bar{V}$, was defined, where $\overline{D D R}$ is the mean density of decayed reproductive shoots. The total differentiation of the number is:

$$
\mathrm{d}(\overline{D D R} \times \bar{V})=\mathrm{d} \overline{D D R} \times \bar{V}+\overline{D D R} \times \mathrm{d} \bar{V}
$$

The first and second terms on the right side of Eq. (2) are realized as variations in the number of vestiges of spathes by varying numbers of decayed reproductive shoots and by varying numbers of vestiges of spathes on the live reproductive shoots that decay during the arbitrary interval.

By discretizing Eq. (2), d $\overline{D D R}$ becomes $\Delta \overline{D D R}$. In addition, $\triangle \overline{D D R}$ can be replaced with the density of decayed reproductive shoots at $m, \overline{D D R_{m}}$, by assuming that the reproductive shoots completely disappear during the sampling interval. The mean density of seeds dispersed by decayed reproductive shoots $\left(d^{\prime}\right), \overline{D S D_{\text {decayed, }, d_{1} m}}$, is determined by multiplying the discretized first term on the right side of Eq. (2) by the mean number of seeds in detached spathes, $\overline{N S s p}$. The equation becomes the following relation:

$$
\overline{D S D_{\text {decayed }, d, m}}=\overline{D D R_{m}} \times\left[\left(\overline{V_{m}}+\overline{V_{m-1}}\right) / 2\right] \times \overline{N S s p}
$$

In addition, $\overline{D D R}$ in the second term of Eq. (2) can be approximated by $\overline{D D R_{m}} / 2$. That is, the mean density of seeds dispersed by spathes $\left(d^{\prime \prime}\right)$, $\overline{D S D_{\text {spathe, } d, m}}$, can be written as follows:

$$
\overline{D S D_{\text {spathe }, d, m}}=\left(\overline{D D R_{m}} / 2\right) \times\left(\overline{V_{m}}-\overline{V_{m-1}}\right) \times \overline{N S s p}
$$

The densities of seeds dispersed by decayed reproductive shoots and by detached spathes were determined by summing $\overline{D S D_{\text {decayed, } b, m}}$ and $\overline{D S D_{\text {decayed, } d, m}}$, and by summing $\overline{D S D_{\text {spathe, }, m, m}}$ and $\overline{D S D_{\text {spathe, } d, m}}$, respectively. Although the probability density of these seed densities was determined only as $p\left(D S D_{\text {decayed, } b, m}\right)$, this factor can be used to assess the variability of seed dispersal because of the relatively high density of seeds disepersed from these components (see 'Results').

The density of seeds dispersed by rhipidia was too low to determine by the above estimation method. Therefore, this density was determined by multiplying the ratio of the number of spathes dispersed by rhipidia to the number of detached spathes dispersed separately per live reproductive shoot by the densities of whole and ripe seeds dispersed by detached spathes.

These seeds with determined origins were defined as the identified dispersed seeds. The proportion of the total number of seeds produced in a year (potential seeds) accounted for by the density of identified dispersed seeds was calculated to assess the accuracy of the above estimations. The density of potential seeds was determined by summing the mean density of whole seeds on live reproductive shoots in June and dispersed by all diaspores by June. The total mean density of whole and ripe seeds dispersed with each diaspore type was determined from the summation of their monthly mean densities. The density of seeds dispersed with detached spathes was separated into those seeds that floated and those that sank by using the proportions resulting from the buoyancy tests.

\section{RESULTS}

\section{Seasonal seed production}

The density of eelgrass shoots, including both vegetative and reproductive shoots, varied during the study period from $123 \pm 61$ shoots $\mathrm{m}^{-2}$ in March to $203 \pm 65$ shoots $\mathrm{m}^{-2}$ (mean \pm SD) in May (Fig. 3A). The density of live reproductive shoots showed a significant monthly variation (Kruskal-Wallis rank-sum test; Kruskal-Wallis $\chi^{2}=77.1, \mathrm{df}=3, \mathrm{p}<0.001$ ), with the maximum density of $45 \pm 27$ shoots $\mathrm{m}^{-2}(21 \% \pm$ $7 \%$ of total shoot density) in May (Fig. 3B).

The number of ripe seeds was significantly lower than that of immature seeds (Wilcoxon signed-rank test; $2009: W^{+}=7.5, \mathrm{p}<0.001 ; 2010: W^{+}=17.5, \mathrm{p}<$ 0.001 ) and increased between May and July in both 2009 (Kruskal-Wallis rank-sum test; KruskalWallis $\left.\chi^{2}=36.8, \mathrm{df}=2, \mathrm{p}<0.001\right)$ and 2010 (Kruskal-Wallis $\chi^{2}=30.1, \mathrm{df}=2, \mathrm{p}<0.001$ ) (Table 2). The whole seed abundance in live reproductive shoots was estimated to peak in June with a mean 


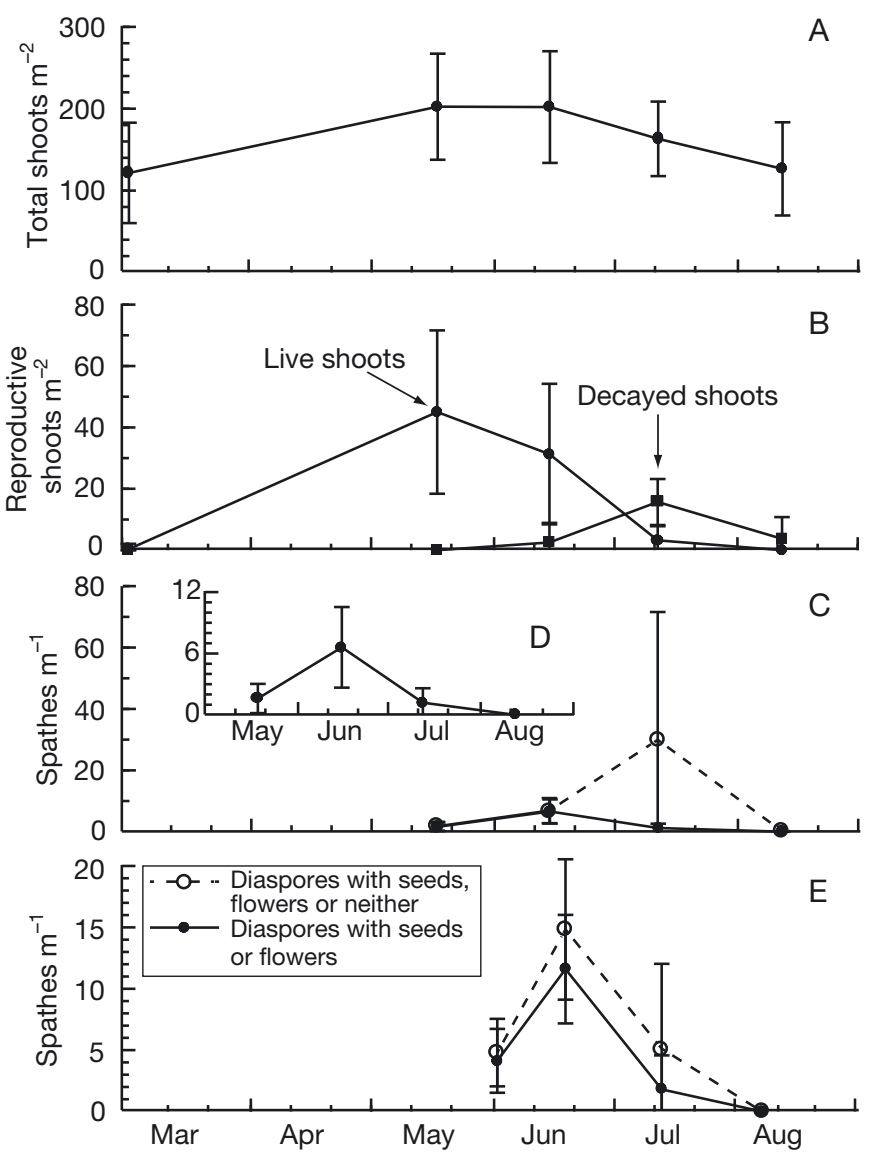

Fig. 3. Seasonal changes in the density of reproductive shoots and the abundance of spathes washed ashore. (A) Density of total shoots (vegetative and reproductive). (B) Density of reproductive shoots (live and decayed). (C) Abundance of diaspores washed up along the shoreline in 2010 ( $n=6$ transects at each monthly sampling). (D) Expanded view of the abundance of diaspores with seeds or flowers. (E) Abundance of diaspores washed up along the shoreline in 2009 ( $n=3$ transects at each sampling). The abundance of diaspores in (C), (D), and (E) is presented as the number of spathes included in the diaspores. Error bars indicate standard deviations

of 2717 seeds $\mathrm{m}^{-2}$ (Fig. 4A), 23-fold greater on average than that of ripe seeds.

\section{Seasonal behavior of diaspores}

Decayed reproductive shoots

Reproductive shoots began decaying in June, with a significant monthly variation (Kruskal-Wallis ranksum test; Kruskal-Wallis $\chi^{2}=56.8, \mathrm{df}=3, \mathrm{p}<0.001$ ), at the same time that the number of live reproductive shoots started decreasing (Fig. 3B). The density of
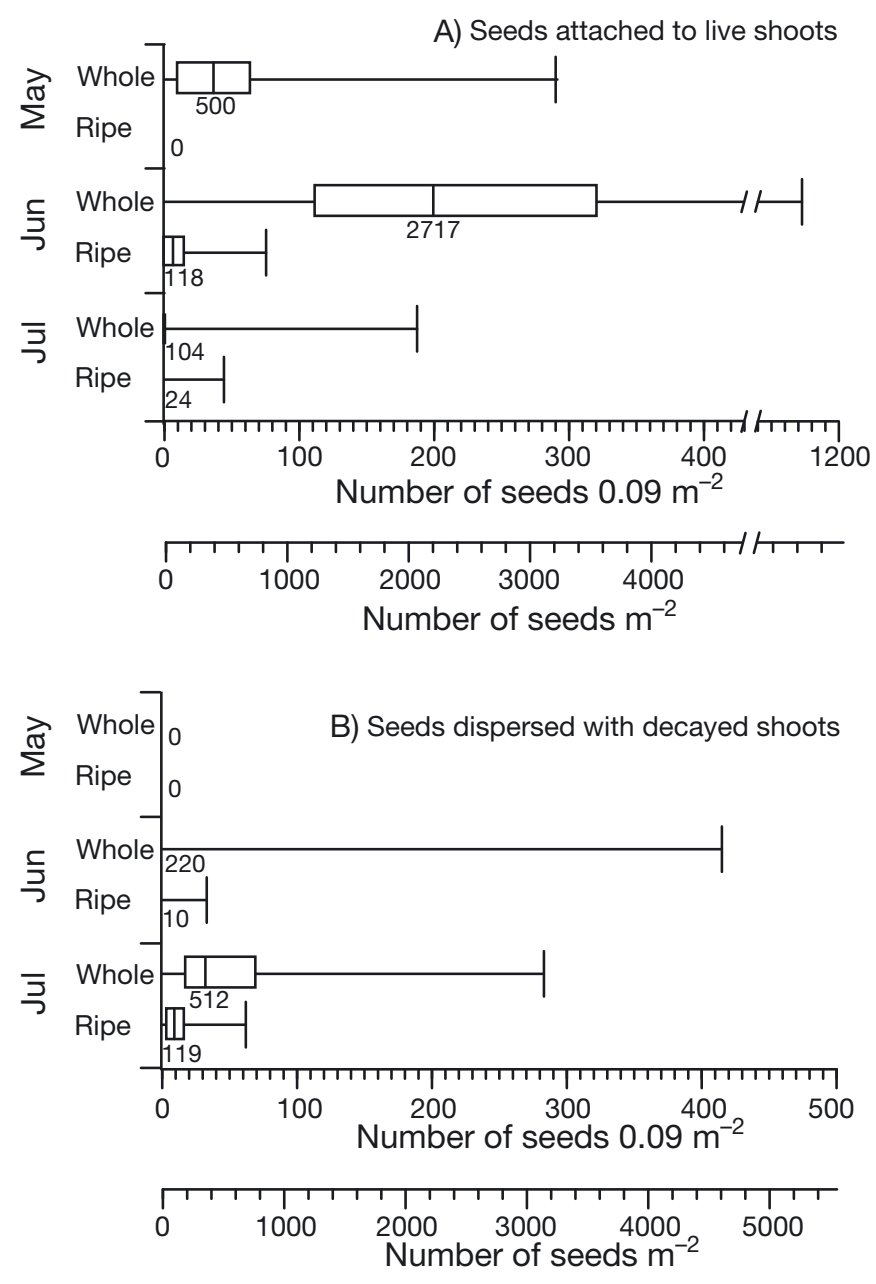

Fig. 4. Box-and-whisker plots for the estimated abundance of (A) seeds attached to live reproductive shoots $D S_{m}$, and (B) seeds dispersed with decayed reproductive shoots, $D S D_{\text {decayed, } b, m}$, including values for whole seeds and ripe seeds. The vertical line inside the box, the box limits, and whiskers show the median, interquartile range, and range, respectively. The number below the median vertical line is the mean value per square meter. Because these abundances were calculated for an area of $0.09 \mathrm{~m}^{2}$, the $x$-axis is shown scaled for $0.09 \mathrm{~m}^{2}$ and standardized to $1 \mathrm{~m}^{2}$

decayed reproductive shoots reached a maximum in July $\left(16 \pm 8\right.$ shoots $\left.\mathrm{m}^{-2}\right)$, at approximately one-third the density of live reproductive shoots in May.

\section{Spathes}

Vestiges of spathes on live reproductive shoots were observed between May and July (Table 2). The number of spathe vestiges on live reproductive shoots reached a maximum in July, with significant monthly differences in both 2009 (Kruskal-Wallis 
Table 2. Numbers of spathes, rhipidia, and seeds in live reproductive shoots and the number of spathes in rhipidia of eelgrass Zostera marina. Spathes and rhipidia are categorized as present (attached to live reproductive shoots) or absent (determined from vestiges). Values are mean \pm 1 SD. The original values for 7 July 2009 were incorrect because it was not possible to identify the parent reproductive shoots of seeds and spathes that became separated after sampling. The corrected mean values are in parentheses; see 'Materials and methods: Reproductive shoots and seed production' for the explanation of corrections

\begin{tabular}{|c|c|c|c|c|c|c|c|c|c|c|c|}
\hline \multirow[t]{3}{*}{ Date } & \multirow{3}{*}{$\mathrm{n}$} & \multicolumn{7}{|c|}{ - Reproductive shoots } & \multicolumn{3}{|c|}{ Rhipidia_- } \\
\hline & & \multicolumn{2}{|c|}{$\begin{array}{l}\text { Spathes } \\
\text { (no. shoot }{ }^{-1} \text { ) }\end{array}$} & \multicolumn{2}{|c|}{ 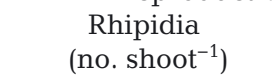 } & \multirow{2}{*}{$\begin{array}{c}\text { Vestiges of } \\
\text { unclear } \\
\text { origin }\end{array}$} & \multirow{2}{*}{$\begin{array}{c}\text { Ripe } \\
\text { seeds } \\
\left(\text { seeds shoot }^{-1} \text { ) }\right.\end{array}$} & \multirow{2}{*}{$\begin{array}{l}\text { Immature } \\
\quad \text { seeds } \\
\text { (seeds shoot }^{-1} \text { ) }\end{array}$} & \multirow[t]{2}{*}{$\mathrm{n}$} & \multicolumn{2}{|c|}{$\begin{array}{c}\text { Spathes } \\
\text { (no. rhipidium }{ }^{-1} \text { ) }\end{array}$} \\
\hline & & Present & Absent & Present & Absent & & & & & Present & Absent \\
\hline \multicolumn{12}{|l|}{2009} \\
\hline 11 May & 20 & $13.5 \pm 6.7$ & $0.1 \pm 0.2$ & $2.5 \pm 1.5$ & $0.1 \pm 0.2$ & $0.2 \pm 0.4$ & $0.0 \pm 0.0$ & $36.8 \pm 34.7$ & 49 & $3.8 \pm 1.6$ & $0.0 \pm 0.1$ \\
\hline 09 Jun & 20 & $23.0 \pm 8.5$ & $2.0 \pm 3.2$ & $3.4 \pm 1.2$ & $0.3 \pm 0.4$ & $0.6 \pm 0.9$ & $2.0 \pm 3.4$ & $51.1 \pm 38.9$ & 68 & $4.9 \pm 1.5$ & $0.5 \pm 1.0$ \\
\hline $07 \mathrm{Jul}$ & 201 & $15.1(16.4) \pm 5.2$ & $6.9(5.6) \pm 4.3$ & $3.5 \pm 1.6$ & $0.1 \pm 0.3$ & $0.4 \pm 0.9$ & $6.4(10.1) \pm 4.9$ & $24.6 \pm 15.9$ & 69 & $3.2 \pm 1.4$ & $1.6 \pm 1.1$ \\
\hline 07 Aug & & & Live & e reproduc & tive shoots & ts were not $p$ & present & & & & \\
\hline \multicolumn{12}{|l|}{2010} \\
\hline 18 May & 20 & $12.1 \pm 5.8$ & $0.3 \pm 0.9$ & $2.9 \pm 1.2$ & $0.0 \pm 0.0$ & $0.0 \pm 0.0$ & $0.0 \pm 0.0$ & $11.1 \pm 15.8$ & 57 & $3.1 \pm 1.1$ & $0.1 \pm 0.3$ \\
\hline 15 Jun & 20 & $22.1 \pm 8.2$ & $1.9 \pm 2.2$ & $3.3 \pm 1.1$ & $0.1 \pm 0.2$ & $0.0 \pm 0.0$ & $3.8 \pm 4.5$ & $82.6 \pm 40.0$ & 66 & $5.5 \pm 1.8$ & $0.5 \pm 0.8$ \\
\hline $12 \mathrm{Jul}$ & 20 & $15.2 \pm 6.6$ & $7.5 \pm 5.5$ & $3.4 \pm 1.3$ & $0.0 \pm 0.0$ & $0.0 \pm 0.0$ & $7.7 \pm 6.3$ & $25.1 \pm 23.4$ & 68 & $4.9 \pm 1.8$ & $2.0 \pm 1.3$ \\
\hline 12 Aug & & & Live & e reproduct & tive shoots & ts were not $p$ & present & & & & \\
\hline
\end{tabular}

rank-sum test; Kruskal-Wallis $\chi^{2}=41.3$, df $=2$, $\mathrm{p}<$ 0.001 ) and 2010 (Kruskal-Wallis $\chi^{2}=31.9$, df $=2, \mathrm{p}<$ 0.001). Vestiges accounted for approximately onethird of the total number of spathes (spathes + spathe vestiges).

\section{Rhipidia}

There were no significant monthly differences in the number of rhipidium vestiges in either 2009 (Kruskal-Wallis $\chi^{2}=3.7$, df $=2, \mathrm{p}=0.16$ ) or 2010 (Kruskal-Wallis $\chi^{2}=2.00$, df $=2, \mathrm{p}=0.37$ ); the maximum was in June 2009 (Table 2). The number of spathes represented by the vestiges of rhipidia on live reproductive shoots was estimated at 1.5 spathes shoot $^{-1}$ in June 2009 and 0.6 spathes shoot ${ }^{-1}$ in June 2010. These values were equal to $75 \%$ and $29 \%$ of the detached spathes counted in each month in 2009 and 2010, respectively.

\section{Buoyancy potential of diaspores}

All seeds examined sank; the specific gravity of ripe seeds (mean $\pm \mathrm{SD}$ ) was $1.13 \pm 0.03(\mathrm{n}=3$ groups of 50 seeds), which was greater than that of the seawater used for the laboratory tests. Of the spathes without seeds, 95\% floated. Of the spathes with seeds, the best model as determined by the AIC showed that there was a negative relationship between the proportion of floating spathes and the number of ripe seeds per spathe; this relationship was more pro- nounced in the detached spathes (Fig. 5, see Table S2 in Supplement 2). The model also showed that a maximum of $43 \%$ of the detached spathes floated (i.e. at least $57 \%$ sank). Of the rhipidia tested, $94 \%$ floated.

The numbers of whole and ripe seeds in the detached spathes $(\mathrm{n}=72)$ were $3.5 \pm 2.3$ and $2.1 \pm 2.3$ seeds spathe ${ }^{-1}$ (mean $\left.\pm \mathrm{SD}\right)$, respectively.

\section{Seeds produced and their destinations}

The density of seeds on live reproductive shoots ranged widely between May and July and was highest in June at 2717 seeds $\mathrm{m}^{-2}$ (Fig. 4A). Seeds were dispersed by decayed reproductive shoots in June and July (Table 3). The estimated densities of seeds dispersed by decayed reproductive shoots were 1000 seeds $\mathrm{m}^{-2}$ as whole seeds and 290 seeds $\mathrm{m}^{-2}$ as ripe seeds, in total over the season. The density of seeds dispersed with decayed reproductive shoots as determined from the density of decayed reproductive shoots and the number of seeds in live reproductive shoots (b) ranged widely (Fig. 4B), being approximately 3 -fold greater than that determined from the density of decayed reproductive shoots, the number of spathe vestiges on live reproductive shoots, and the number of seeds in spathe vestiges $\left(d^{\prime}\right)$ (Table 3 ). Seeds were dispersed by detached spathes beginning in May, earlier than dispersal by decayed reproductive shoots. The densities of seeds dispersed by detached spathes were 446 seeds $\mathrm{m}^{-2}$ as whole seeds and 268 seeds $\mathrm{m}^{-2}$ as ripe seeds. Based on the proportion of sinking 
spathes $(57 \%)$, at least 254 whole seeds $\mathrm{m}^{-2}$ and 153 ripe seeds $\mathrm{m}^{-2}$ were estimated to have been dispersed by detached spathes with negative buoyancy. That is, in total, 1254 whole seeds $\mathrm{m}^{-2}$ and
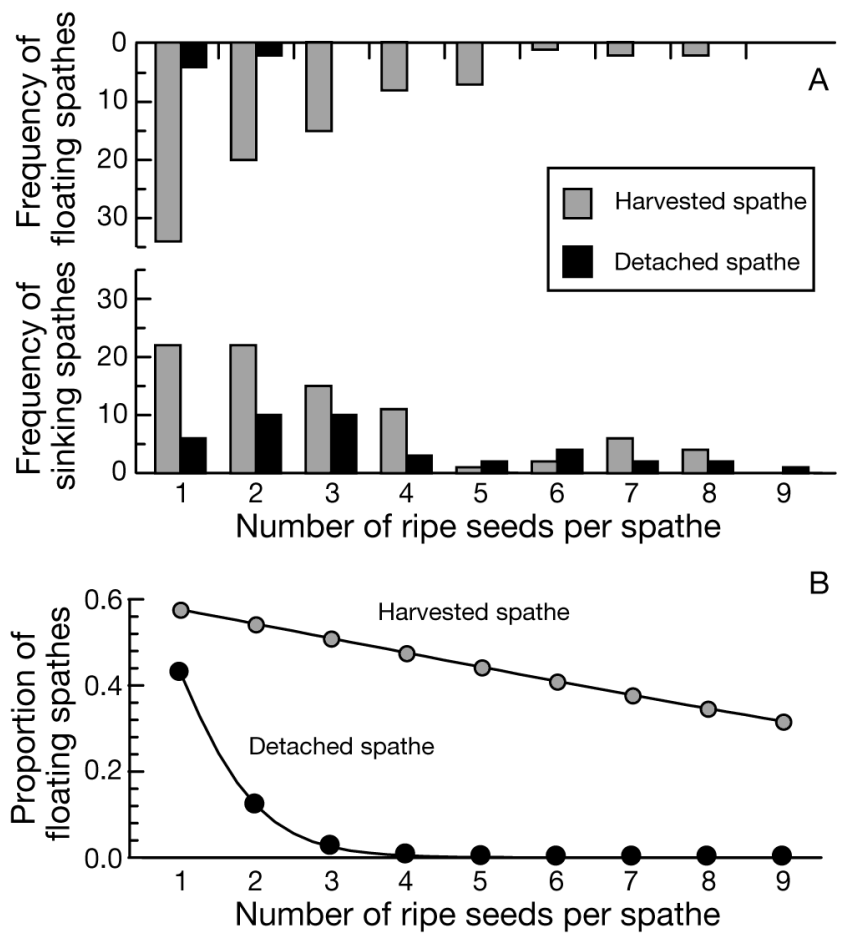

Fig. 5. (A) Buoyancy potential of detached spathes and those harvested from reproductive shoots. Bars indicate the frequencies of sinking and floating spathes with different numbers of ripe seeds. Black and grey bars represent detached spathes and those harvested from reproductive shoots, respectively. (B) Estimated proportion of floating spathes among harvested and detached spathes. Solid lines show the maximum likelihood estimates for detached spathes (black circles) and harvested spathes (grey circles), which were derived from the best generalized linear model as determined from the Akaike information criterion
443 ripe seeds $\mathrm{m}^{-2}$ were estimated to have been dispersed by the negatively-buoyant diaspores: decayed reproductive shoots and sinking spathes. Because the rhipidia contributed $29 \%$ of the detached spathes, seeds dispersed by rhipidia were estimated to be 53 seeds $\mathrm{m}^{-2}$ as whole seeds and 32 seeds $\mathrm{m}^{-2}$ as ripe seeds.

The density of potential seeds in 2010 was calculated as 3229 seeds $\mathrm{m}^{-2}$. Thus, the seeds dispersed by decayed reproductive shoots and by detached spathes accounted for $31 \%$ and $14 \%$ of the total potential seeds, respectively. In addition, an estimated minimum of $8 \%$ of the potential seeds had negative buoyancy, considering the percentage of sinking spathes. The seeds dispersed by rhipidia were estimated to equal almost $2 \%$. These estimates indicate that, of the seeds for which the mode of dispersal and fate were determined, at least $84 \%$ had negative buoyancy. The fate of the remaining 1730 seeds $\mathrm{m}^{-2}$ (54\% of the total potential seeds) was not determined.

\section{Diaspores along the shoreline}

Diaspores were observed washed up along the shoreline from May to July, and they were not detected in August when there were no live reproductive shoots (Fig. 3B,C). The abundance of diaspores onshore with seeds or flowers peaked in June 2010 (Fig. 3D; Kruskal-Wallis $\chi^{2}=18.4$, df $=3$, p < 0.001 ). Seasonal variation of diaspores with seeds or flowers was evident in 2009 (Fig. 3E; Kruskal-Wallis $\left.\chi^{2}=9.8, \mathrm{df}=3, \mathrm{p}<0.05\right)$. The total number of diaspores, including those without any seeds or flowers, was highly variable in July 2010, but not in July 2009.

The best model as determined by the AIC for describing the proportion of separated spathes in

Table 3. Mean densities of seeds on live reproductive shoots and of dispersed seeds (seeds $\mathrm{m}^{-2}$ ). $D S_{m}$ is the density of seeds on live reproductive shoots in month $m$. $D S D_{\text {decayed, } m}, D S D_{\text {spathe, } m \text {, }}$ and $D S D_{\text {rhipidium, } m}$ are the densities of seeds dispersed by decayed reproductive shoots, by spathes, and by rhipidia respectively, between months $m-1$ and $m$. These values were not estimated in August because live reproductive shoots, by which these values are estimated, were not detected. $a, b, c, d^{\prime}$, and $d^{\prime \prime}$ are defined in Table 1 .

Values in parentheses are the proportions (percentages) of seeds relative to the density of total potential seeds $\left(3229 \mathrm{seeds}^{-2}\right.$ )

\begin{tabular}{|c|c|c|c|c|c|c|c|c|c|c|c|c|c|c|c|c|}
\hline \multirow[t]{2}{*}{$\begin{array}{l}\text { Month } \\
(m)\end{array}$} & \multicolumn{2}{|c|}{$\begin{array}{c}-D S_{m}- \\
a\end{array}$} & \multicolumn{4}{|c|}{$-D S D_{\text {decayed }, m}-$} & \multicolumn{2}{|c|}{ Total } & \multicolumn{2}{|c|}{ C } & \multicolumn{2}{|c|}{$\begin{array}{c}-D S D_{\text {spathe }, m} \\
d^{\prime \prime}\end{array}$} & \multicolumn{2}{|c|}{ Total } & \multicolumn{2}{|c|}{$\begin{array}{c}D S D_{\text {rhipidium }, m} \\
\text { Total }\end{array}$} \\
\hline & Whole & Ripe & Whole & Ripe & Whole & Ripe & Whole & Ripe & Whole & Ripe & Whole & Ripe & Whole & Ripe & Whole & Ripe \\
\hline Jun (2) & 2717 & 118 & 220 & 10 & 10 & 6 & 230 & 16 & 175 & 105 & 7 & 4 & 182 & 109 & 53 & 32 \\
\hline Jul (3) & 104 & 24 & 512 & 119 & 258 & 155 & 770 & 274 & 63 & 38 & 154 & 92 & 217 & 130 & 0 & 0 \\
\hline Total & & & $732(23)$ & $129(4)$ & $268(8)$ & 161 (5) & $1000(31)$ & $290(9)$ & $285(9)$ & 171 & $161(5)$ & $97(3)$ & 446 (14) & $268(8)$ & $53(2)$ & $32(1)$ \\
\hline
\end{tabular}



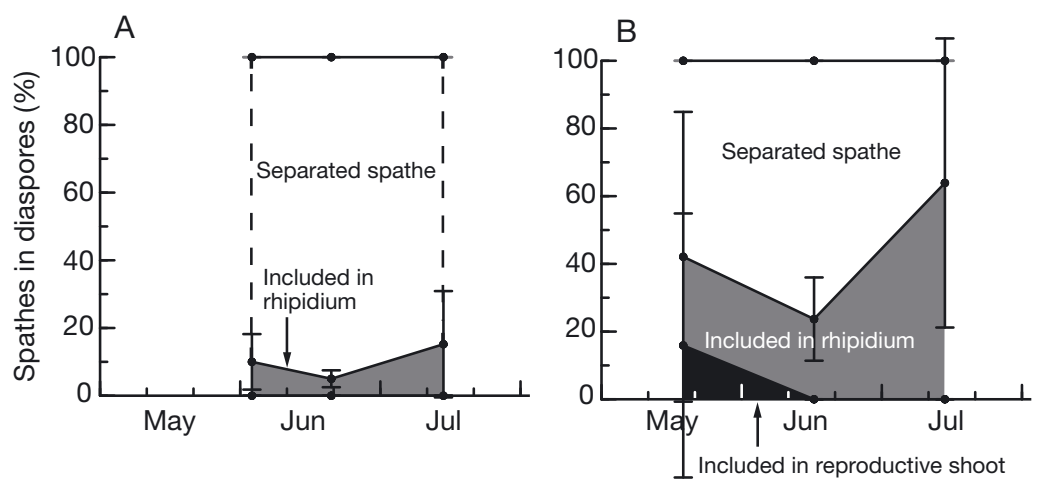

Fig. 6. Relative proportions of different diaspore types washed ashore in (A) 2009 and (B) 2010. Error bars indicate standard deviations $\mathrm{m}^{-2}$ in May (before seed dispersal). The scale parameter of the random effect in the AIC-selected best model was 1.1 (Table S4), which produced a SD up to 3.1-fold greater than the MLE.

The selected model shows an increase in the abundance of seed-coat fragments in the sediment with increasing date through the year, in contrast to the decreasing number of seeds in the sediment, and a positive relationship with the presence of vegetation, similar to the trend for seeds in the sediment (Fig. 7B, Table S4). In the selected model, the MLE for the

diaspores showed that the primary diaspore was the separated spathe $77 \%$ in the maximum likelihood estimation [MLE] and 69 to $83 \%$ in standard error [SE]), and the second most common was the rhipidium $(19 \%$ in MLE and 14 to $25 \%$ in SE) (Fig. 6A,B, see Table S3 in Supplement 2). However, the proportions ranged widely: 36 to $95 \%$ for separated spathes, accounting for the scale parameter (1.7), and 5 to $55 \%$ for rhipidia (scale parameter, 1.6). The relative proportions of the various diaspores were not related to the month (Date) or year (Year: 2009 or 2010). A single reproductive shoot was observed onshore only in May 2010, but the MLE was zero.

\section{Seeds in sediment}

The density of seeds in the sediment within vegetation varied between 78 and 4000 seeds $\mathrm{m}^{-2}$ in August and decreased with date in the best-fit model as determined by the AIC (Fig. 7A, see Table S4 in Supplement 2). The best-fit model also showed that the density of seeds in the sediment was positively related to the presence of vegetation. The MLE in the best model for the density of seeds was 204 seeds $\mathrm{m}^{-2}$ within vegetation and 19 seeds $\mathrm{m}^{-2}$ outside of vegetation on the sampling day in August, whereas the density within vegetation was $7 \pm 15$ seeds
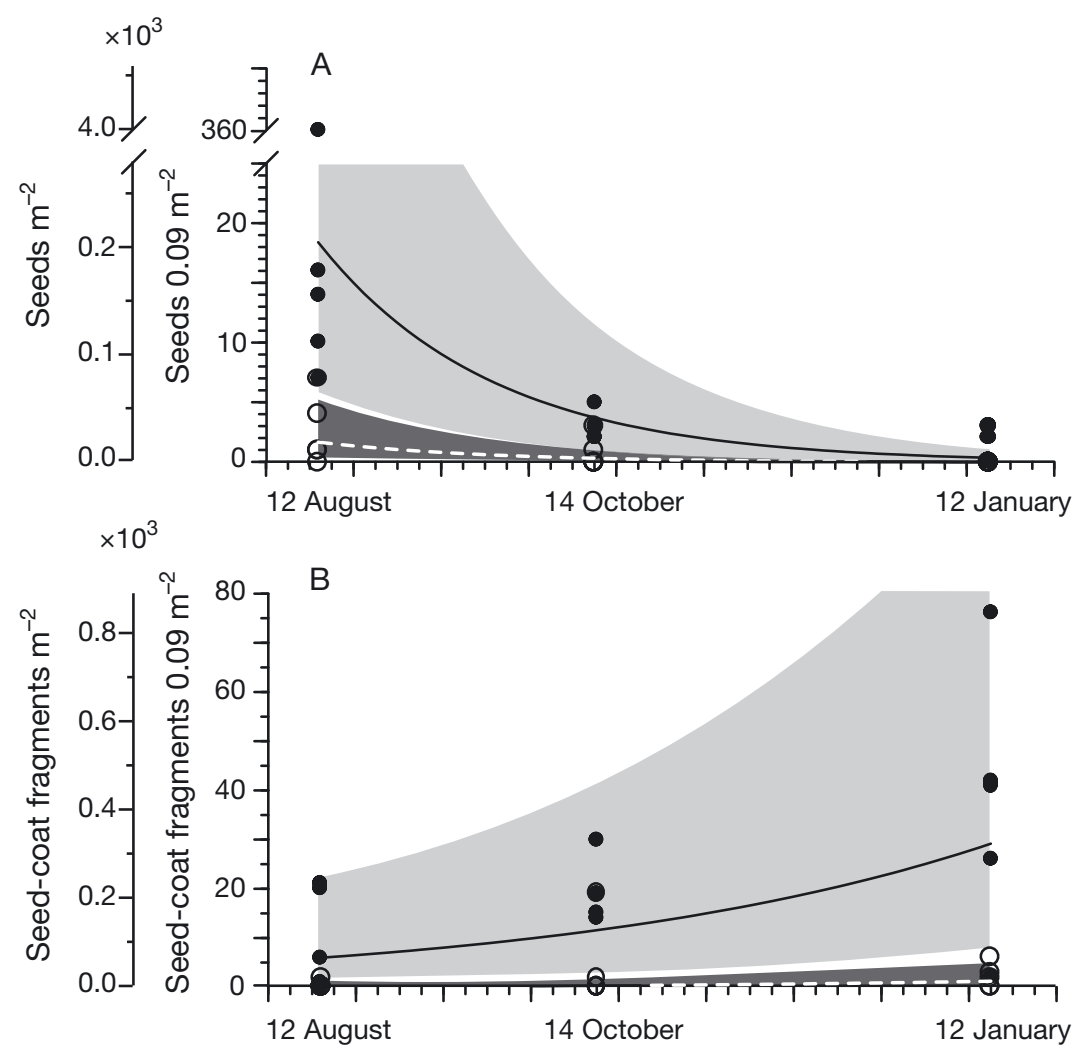

Fig. 7. Abundance in the sediment of (A) seeds and (B) seed-coat fragments. Filled and open circles indicate measured values from within and outside of vegetated areas, respectively. Solid and dashed lines are the maximum likelihood estimates for values within and outside of vegetated areas, respectively, which are based on the results of the best-fit generalized linear mixed model as determined from the Akaike information criterion. Shading indicates the range of the standard deviations calculated as random effects. Because these abundances were measured for an area of $0.09 \mathrm{~m}^{2}$, the $y$-axis is shown scaled for $0.09 \mathrm{~m}^{2}$ and standardized to $1 \mathrm{~m}^{2}$ 
greater than the MLE. The abundance of seed-coat fragments was $216 \pm 199$ fragments $\mathrm{m}^{-2}$ in May (before seed dispersal).

Seedlings were found only in January 2011, with a density of $11 \pm 25$ seedlings $\mathrm{m}^{-2}$ (mean $\pm \mathrm{SD}$ ) within vegetation. This density accounted for $0.3 \%$ of the potential seeds and $5 \%$ of seeds in the sediment within vegetation from August of the previous year.

\section{DISCUSSION}

Our field surveys and buoyancy experiment showed that decayed reproductive shoots dispersed seeds in the parent bed late in the reproductive season and that they dispersed the majority of the identified dispersed seeds (Fig. 8). Spathes were the secondary diaspores that dispersed seeds both within the parent bed and by rafting. Rhipidia, which were also rafted, were quantitatively minor vectors for seed dispersal. This study quantified the sequence of seed production and the role of diaspores in seed dispersal; the present work is the first to show that eelgrass has various diaspores with different dispersal mechanisms, but that most seed dispersal at a calm site is near or within the parent bed.

\section{Seed production and dispersal}

An estimated $39 \%$ of the total potential seeds, accounting for $84 \%$ of the identified dispersed seeds, were dispersed via decayed reproductive shoots and negatively buoyant spathes (Fig. 8). This proportion could be as high as $45 \%$ considering that in the field the proportion of negatively buoyant spathes would be higher because spathes with $\geq 2$ seeds have greater negative buoyancy than spathes with a single seed. Considering this uncertainty, the abundance of ripe seeds dispersed by these diaspores is estimated to range from 443 to 558 seeds $\mathrm{m}^{-2}$, which is 2- or 3fold greater than the MLE of the density of seeds in sediment in August.

The spathe buoyancy tests showed that seeds in detached spathes settle out of the water column, but did not reveal how far the seeds dispersed during settling. However, the close agreement between the counts of ripe seeds and of seeds in the sediment, which were very low before seed dispersal, strongly suggests that at least one-third to one-half of the seeds were dispersed into the parent bed. Because the first count of seeds in the sediment occurred a month after the counts of dispersed seeds, the density of seeds in the sediment immediately after dispersal was likely closer to the density of dispersed seeds. In addition, the greater abundance of seeds in the sedi-

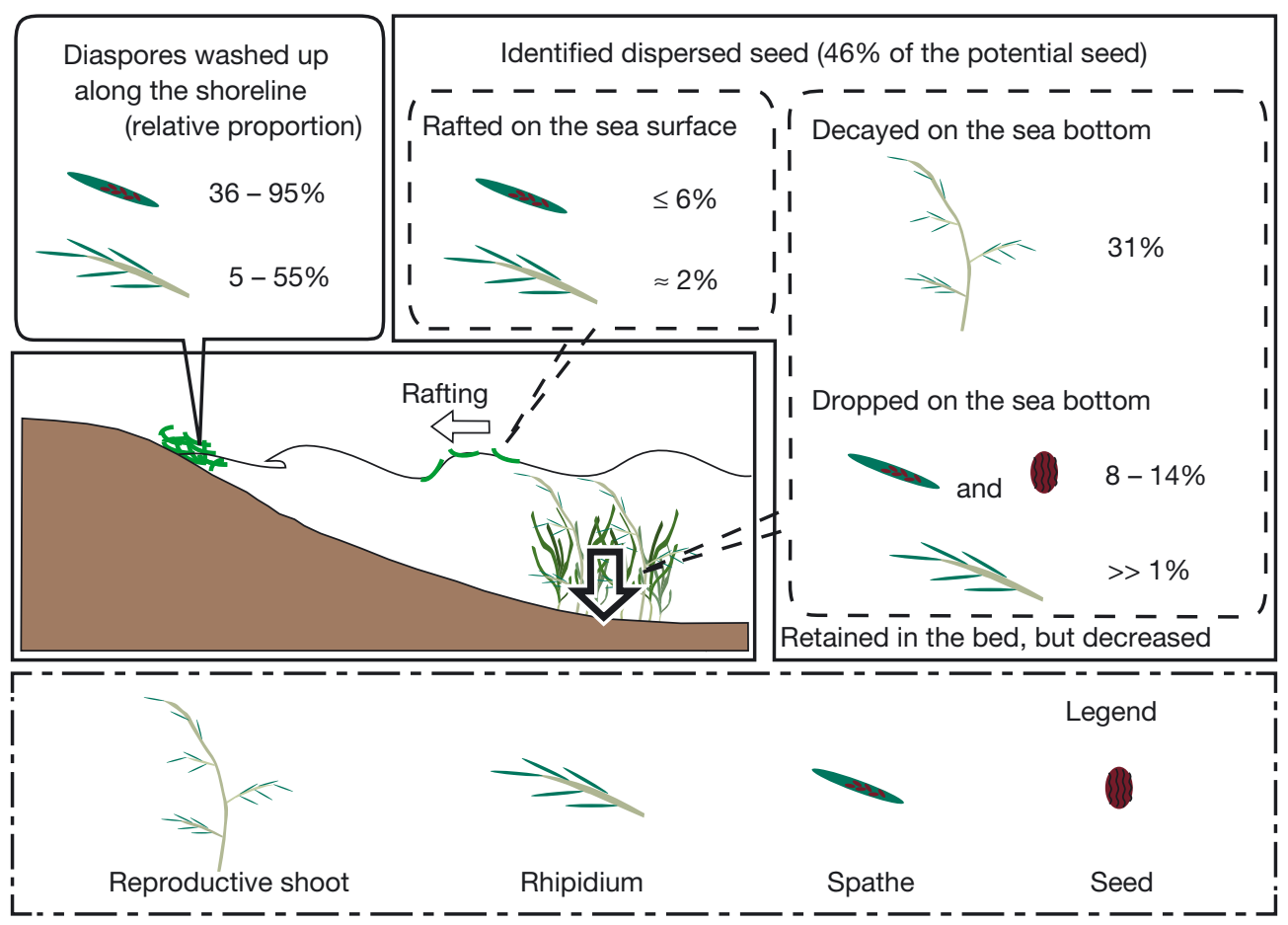

Fig. 8. Schematic showing the proportional dispersal of identified Zostera marina seeds 
ment within vegetation than outside of vegetation strongly suggests that these seeds are retained in the parent bed, possibly because of hydrodynamic resistance to mass transport within vegetation (Abdelrhman 2003). There is still the possibility that seeds from outside the parent bed were trapped by the vegetation within the bed. However, seeds in the sediment would most likely originate from the parent bed because the influx of seeds from outside Kurihama Bay would almost certainly be inhibited by the location and orientation of the bay (i.e. its position facing the Pacific Ocean) and its enclosed geometry resulting from its modifications as a port facility.

Our data for reproductive shoots and seed production indicate that decayed reproductive shoots were the main diaspore (Fig. 8). Conversely, although turbulent diffusion in shallow-water areas can cause surface-water mass transfer to a shoreline (Nadaoka et al. 1989), and we found diaspores washed up along the shoreline, the abundance of washed-up reproductive shoots was low. These observations support the conclusion that the contribution of reproductive shoots to seed dispersal by rafting is minor. In contrast, the prevalence of seed dispersal through decayed reproductive shoots would have been encouraged by the calm conditions (no typhoons) during the observations in 2010 (Japan Meteorological Agency, www.jma.go.jp/jma/indexe.html). Even if the bay experienced high-energy waves from the Pacific Ocean, the protection afforded by the port features such as breakwaters would likely maintain relatively low disturbance at the site (Yasuda et al. 2003).

Our investigations into the vestiges of spathes and the seed production they represent showed that spathes should also be considered a quantitatively important diaspore (Fig. 8). In addition, our buoyancy tests indicated that most of the spathes were dispersed into the parent bed. The negative buoyancy of detached spathes was largely a consequence of the weight of the ripe seeds they contained, which had greater specific gravity than seawater. Conversely, spathes harvested from live reproductive shoots and detached spathes with few or no ripe seeds had large positive buoyancy resulting from their buoyant live tissue. The relative proportions of floating and sinking spathes may vary, however, because of different combinations of the specific gravity of seeds, tissue conditions degrading over time, and other conditions such as the amounts of epiphytes or epifauna. In other words, spathes have the potential to be a major diaspore, dispersing seeds far from the parent bed by rafting.
Rhipidia were considered to be minor diaspores for dispersing seeds. However, the relative abundances of rhipidia washed ashore were comparable to those of spathes (Fig. 8). Assuming that the numbers of diaspores washed up along the shoreline reflects the numbers of floating diaspores, rhipidia could be comparable to spathes as rafting diaspores. The positive buoyancy of rhipidia probably results from parts that are more buoyant compared to separated spathes. The high variability in the relative abundance of rhipidia washed ashore is likely caused by variations in their number of spathes.

The timing of seed dispersal differed between diaspores. Although seed dispersal by detached spathes increased by July as did that by decayed reproductive shoots, dispersal by detached spathes started earlier than that by decayed reproductive shoots. In contrast to the increase in seed dispersal by these diaspores, the detachment of rhipidia was not related to the date, although the timing of diaspore dispersal is suspected to be related to ontogenetic degradation and hydrodynamic regimes (Källström et al. 2008). The physical connection between rhipidia and the live reproductive shoot would be stronger than the connection between spathe and rhipidium. Although we suspect from our results for the timing of diaspores that the proportion of separated spathes washed up along the shoreline is related to the date, the statistical models that included this relationship were not selected as the best fit. The relatively high variability in the numbers of rhipidia washed ashore would have masked any date-related effects on the proportion. Any effects resulting from the difference in sampling methods along the shoreline between 2009 and 2010 would be also hidden by the high variability in rhipidium abundance.

The $54 \%$ of potential seeds that were unidentified could have been immature, consumed before ripening (Nakaoka 2002, Alexandre et al. 2006), or dispersed out of the parent bed. The unidentified potential seeds were mainly generated during a decrease in the abundance of live reproductive shoots in June and July, which was reflected in relatively higher abundances of diaspores washed up on shore in July (Fig. 3C). However, most of these consisted of diaspores without any seeds or flowers. This pattern suggests that the unidentified potential seeds were dispersed but may not have developed into ripe seeds. In addition, the close agreement between the abundance of seeds in the sediment and the abundance of identified ripe seeds suggests that unidentified seeds play a minor role in dispersal into the parent bed. The unexplained loss of immature seeds could be 
caused by such things as the short reproductive period (Alexandre et al. 2006) or grazing by epifauna (Nakaoka 2002), but the cause is not clear from this study.

\section{Recruitment from seeds after dispersal}

The contrasting patterns of variation in seeds and seed-coat fragments reflect the replacement of seeds retained in the parent bed with seed-coat fragments through biological processes such as grazing and decomposition that cause a decrease in the number of seeds in the sediment (Harrison 1993, Probert \& Brenchley 1999, Orth et al. 2003). The processes seemed to be more evident in the early months after dispersal because of an immediate decrease in numbers of seeds in the sediment (Fig. 7A). This pattern is probably because there is a high risk of predation by crabs, snails, and fishes (Wigand \& Churchill 1988, Fishman \& Orth 1996, Marion \& Orth 2012). The immediate decrease in seeds in the sediment after seed dispersal would have a critical effect on the recruitment rate and would result in a recruitment rate of $5 \%$ at this site.

The recruitment rate of $5 \%$ from seeds to seedlings found in this study is close to those found in a previous study on unvegetated sea bottoms, ranging from 2 to $7 \%$ (Orth et al. 2012). However, the recruitment rate in the present study had high variability, possibly caused by the heterogeneity in the abundance of seeds in the sediment (Fig. 7A). This heterogeneity is believed to be caused by sediment properties such as topographic sheltering (Inglis 2000) and the seedtrapping capability of biotic agents (Harwell \& Orth 2001) after seed dispersal. In addition, the heterogeneity of seed distribution in the sediment could reflect a high degree of heterogeneity in seed production (Fig. 4A) and in the density of dispersed seed described by $b$ (Fig. $4 \mathrm{~B}$; see Table 1 ), which was a quantitatively important mode of seed dispersal in the parent bed (Table 3). If high seed density has a negative effect on seed growth to seedling, as has been shown for other seagrass species (Balestri \& Lardicci 2008, Balestri et al. 2010) but not for eelgrass (Orth et al. 2003), then the heterogeneity of seed production may also be a factor in determining recruitment rate.

\section{General implications}

This study of eelgrass reveals that most of the seeds produced were dispersed by decayed reproductive shoots and detached spathes within the area of parent plants (beds). Indeed, the phenomenon in eelgrass whereby most seeds are dispersed into the parent bed has also been shown in the York River, Virginia, USA (Orth et al. 1994). Although wider seed dispersal is advantageous for escaping disproportionate mortality near the parent plant, through colonization of suitable sites that are unpredictable in time and space (Howe \& Smallwood 1982), this advantage would not be significant for eelgrass at a calm site.

This study also reveals that the abundance of seeds dispersed through rafting as positively buoyant spathes and rhipidia was relatively low, although many previous studies have stressed the importance of floating diaspores for population expansion (Orth et al. 1994, Harwell \& Orth 2002, Erftemeijer et al. 2008, Källström et al. 2008). Our findings indicate that the spread of eelgrass populations at landscape scales hinges on a small portion of the potential seeds produced. However, because the magnitude of hydrodynamic forces (Patterson et al. 2001) and hydrodynamic regimes, as well as ontogenetic degradation (Källström et al. 2008), may affect the abundance of diaspores and the timing of their detachment, their dispersal properties may vary among sites.

Seed dispersal at calm sites will be mainly within the parent bed. This dispersal pattern seems to play a role in population maintenance (Plus et al. 2003, Greve et al. 2005, Lee et al. 2007) and in increasing genotypic diversity within the parent population (Hughes \& Stachowicz 2011). Conversely, because rapid and certain landscape-scale expansion may require the large-scale distribution of many seeds, the expansion of eelgrass beds from calm sites may depend on forces that result in detached diaspores with positive buoyancy (Patterson et al. 2001, Källström et al. 2008), such as storms or harvesting that involves the manual dispersal of diaspores before they lose their positive buoyancy.

Acknowledgements. We thank E. Saito, K. Seike, and M. Banno for help in the field and laboratory experiments; and S. Yanagishima for the supplemental data concerning sand grain size at the sites around our study site. We thank T. Inoue, H. Kamauchi, K. Honda, K. Watanabe, and $\mathrm{T}$. Yamakita for their valuable comments. Finally, we thank the anonymous reviewers for helpful comments on an earlier version of this paper.

\section{LITERATURE CITED}

Abdelrhman MA (2003) Effect of eelgrass Zostera marina canopies on flow and transport. Mar Ecol Prog Ser 248: $67-83$ 
Alexandre A, Cabaço S, Santos R, Serrão EA (2006) Timing and success of reproductive stages in the seagrass Zostera noltii. Aquat Bot 85:219-223

Bakker JP, Poschlod P, Strykstra RJ, Bekker RM, Thompson K (1996) Seed banks and seed dispersal: important topics in restoration ecology. Acta Bot Neerl 45:461-490

Balestri E, Lardicci C (2008) First evidence of a massive recruitment event in Posidonia oceanica: spatial variation in first-year seedling abundance on a heterogeneous substrate. Estuar Coast Shelf Sci 76:634-641

Balestri E, Vallerini F, Lardicci C (2010) Effect of seed density and sediment nutrient heterogeneity on recruitment and early patch growth in the seagrass Cymodocea nodosa. Mar Ecol Prog Ser 417:63-72

Bischoff A (2002) Dispersal and establishment of floodplain grassland species as limiting factors in restoration. Biol Conserv 104:25-33

> Boedeltje G, Bakker JP, Brinke AT, Van Groenendael JM, Soesbergen M (2004) Dispersal phenology of hydrochorous plants in relation to discharge, seed release time and buoyancy of seeds: the flood pulse concept supported. J Ecol 92:786-796

> Bolker BM, Brooks ME, Clark CJ, Geange SW, Poulsen JR, Stevens MHH, White JSS (2009) Generalized linear mixed models: a practical guide for ecology and evolution. Trends Ecol Evol 24:127-135

> Broström G, Holmberg H (2011) Generalized linear models with clustered data: fixed and random effects models. Comput Stat Data Anal 55:3123-3134

Burnham KP, Anderson DR (2002) Model selection and multimodel inference: a practical information-theoretic approach. Springer, New York, NY

> Coleman MA, Chambers J, Knott NA, Malcolm HA, Harasti D, Jordan A, Kelaher BP (2011a) Connectivity within and among a network of temperate marine reserves. PLoS ONE 6:e20168

> Coleman MA, Roughan M, Macdonald HS, Connell SD, Gillanders BM, Kelaher BP, Steinberg PD (2011b) Variation in the strength of continental boundary currents determines continent-wide connectivity in kelp. J Ecol 99:1026-1032

Erftemeijer PLA, Van Beek JKL, Ochieng CA, Jager Z, Los HJ (2008) Eelgrass seed dispersal via floating generative shoots in the Dutch Wadden Sea: a model approach. Mar Ecol Prog Ser 358:115-124

> Fishman JR, Orth RJ (1996) Effects of predation on Zostera marina L. seed abundance. J Exp Mar Biol Ecol 198: $11-26$

Granger S, Traber MS, Nixon SW, Keyes R (2002) Collection, processing, and storage. In: Schwartz M (ed) A practical guide for the use of seeds in eelgrass (Zostera marina L.) restoration. Rhode Island Sea Grant, Narragansett, RI

> Greve TM, Krause-Jensen D, Rasmussen MB, Christensen PB (2005) Means of rapid eelgrass (Zostera marina L.) recolonisation in former dieback areas. Aquat Bot 82: 143-156

Guo X, Yanagi T (1996) Seasonal variation of residual current in Tokyo Bay, Japan-diagnostic numerical experiments. J Oceanogr 52:597-616

> Harrison PG (1993) Variations in demography of Zostera marina and $Z$. noltii on an intertidal gradient. Aquat Bot 45:63-77

> Harwell MC, Orth RJ (2001) Influence of a tube-dwelling polychaete on the dispersal of fragmented reproductive shoots of eelgrass. Aquat Bot 70:1-7
Harwell MC, Orth RJ (2002) Long-distance dispersal potential in a marine macrophyte. Ecology 83:3319-3330

> Howe F, Smallwood J (1982) Ecology of seed dispersal. Annu Rev Ecol Syst 13:201-228

Hughes AR, Stachowicz JJ (2011) Seagrass genotypic diversity increases disturbance response via complementarity and dominance. J Ecol 99:445-453

> Hurvich CM, Tsai CL (1989) Regression and time series model selection in small samples. Biometrika 76:297-307

> Inglis GJ (2000) Disturbance-related heterogeneity in the seed banks of a marine angiosperm. J Ecol 88:88-99

> Källström B, Nyqvist A, Åberg P, Bodin M, André C (2008) Seed rafting as a dispersal strategy for eelgrass (Zostera marina). Aquat Bot 88:148-153

Kendrick GA, Waycott M, Carruthers TJB, Cambridge ML and others (2012) The central role of dispersal in the maintenance and persistence of seagrass populations. Bioscience 62:56-65

Lee KS, Park JI, Young KK, Sang RP, Kim JH (2007) Recolonization of Zostera marina following destruction caused by a red tide algal bloom: the role of new shoot recruitment from seed banks. Mar Ecol Prog Ser 342:105-115

Marion SR, Orth RJ (2012) Seedling establishment in eelgrass: seed burial effects on winter losses of developing seedlings. Mar Ecol Prog Ser 448:197-207

Morita T, Okumura H, Abe M, Kurashima A, Maegawa M (2007) Density and distribution of seeds in bottom sediments in Zostera marina beds in Ago Bay, central Japan. Aquat Bot 87:38-42

Nadaoka K, Hino M, Koyano Y (1989) Structure of the turbulent flow field under breaking waves in the surface zone. J Fluid Mech 204:359-387

Nakaoka M (2002) Predation on seeds of seagrasses Zostera marina and Zostera caulescens by a tanaid crustacean Zeuxo sp. Aquat Bot 72:99-106

Nakaoka M, Aioi K (2001) Ecology of seagrasses Zostera spp. (Zosteraceae) in Japanese waters: a review. Otsuchi Mar Sci 26:7-22

Nathan R, Muller-Landau HC (2000) Spatial patterns of seed dispersal, their determinants and consequences for recruitment. Trends Ecol Evol 15:278-285

Nathan R, Katul GG, Horn HS, Thomas SM and others (2002) Mechanisms of long-distance dispersal of seeds by wind. Nature 418:409-413

> Orth RJ, Luckenbach M, Moore KA (1994) Seed dispersal in a marine macrophyte: implications for colonization and restoration. Ecology 75:1927-1939

> Orth RJ, Fishman JR, Harwell MC, Marion SR (2003) Seeddensity effects on germination and initial seedling establishment in eelgrass Zostera marina in the Chesapeake Bay region. Mar Ecol Prog Ser 250:71-79

> Orth RJ, Moore KA, Marion SR, Wilcox DJ, Parrish DB (2012) Seed addition facilitates eelgrass recovery in a coastal bay system. Mar Ecol Prog Ser 448:177-195

> Patterson MR, Harwell MC, Orth LM, Orth RJ (2001) Biomechanical properties of the reproductive shoots of eelgrass. Aquat Bot 69:27-40

Phillips RC, Grant WS, McRoy CP (1983) Reproductive strategies of eelgrass (Zostera marina L.) (Gulf of California). Aquat Bot 16:1-20

> Plus M, Deslous-Paoli JM, Dagault F (2003) Seagrass (Zostera marina L.) bed recolonisation after anoxiainduced full mortality. Aquat Bot 77:121-134

Probert RJ, Brenchley JL (1999) The effect of environmental factors on field and laboratory germination in a popula- 
tion of Zostera marina L. from southern England. Seed Sci Res 9:331-339

R Development Core Team (2013) R: a language and environment for statistical computing. R Foundation for Statistical Computing, Vienna, available at www.R-project.org/

Shoji Y, Hasegawa K (2004) Distribution of eelgrass Zostera marina of coastal sea waters in Chiba Prefecture. Bull Chiba Prefectural Fish Res Cent 3:77-86 (in Japanese)

Sumoski SE, Orth RJ (2012) Biotic dispersal in eelgrass Zostera marina. Mar Ecol Prog Ser 471:1-10

Editorial responsibility: Just Cebrian,

Dauphin Island, Alabama, USA
Tanaka N, Demise T, Ishii M, Shoji Y, Nakaoka M (2011) Genetic structure and gene flow of eelgrass Zostera marina populations in Tokyo Bay, Japan: implications for their restoration. Mar Biol 158:871-882

Wigand C, Churchill AC (1988) Laboratory studies on eelgrass seed and seedling predation. Estuaries 11:180-183

Yasuda T, Hattori M, Hiraishi T, Hirayama $K$, Nagai N, Ogawa H (2003) Damage cause and characteristics of wave overtopping in Kurihama Bay. Rep Port Airport Res Inst 42:193-220 (in Japanese with English abstract)

Submitted: April 11, 2014; Accepted: November 28, 2014 Proofs received from author(s): March 2, 2015 